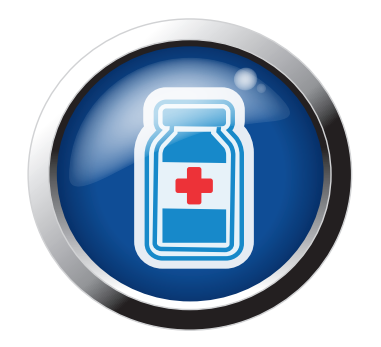

\title{
Correct storage of medicines, dispensary management and standard operating procedures
}

\section{KEY POINTS}

- Medicines must only be stored in secure locations

- Medicines should be stored in accordance with their datasheet or summary of product characteristics (SPC)

- Environmental conditions where medicines are stored must be monitored

\section{Storage of medicines}

\section{Premises}

To enable the Veterinary Medicines Directorate (VMD) to fulfil its obligations under European law to maintain and improve traceability of, and accountability for, veterinary medicines, all premises from which medicines are to be prescribed and supplied must be registered as Veterinary Practice Premises (VPP) with the Royal College of Veterinary Surgeons (RCVS). All registered premises are inspected by the VMD, except those practices who are members of the RCVS Practice Standards Scheme which are inspected by the RCVS as part of this scheme. () See also Registration of premises and inspections.

A VPP must be a permanent building or part of a permanent building, be clean, well maintained and vermin proof. Premises where medicines are held should be capable of being secured to deter intruders. Controlled Drugs and injection equipment are attractive not only to drug misusers but also to professional criminals. Professional advice should be obtained on the suitability of the premises, locks, shutters, security alarms and so forth.

Areas of the practice used for the storage or supply of medicines must not be residential, and public access should be denied or controlled to areas where 'prescription-only medicine - veterinarian' (POM-V), 'prescription-only medicine - veterinarian, pharmacist, suitably qualified persons (SQP)' (POM-VPS) and 'non-food animal - veterinarian, pharmacist, SQP' (NFA-VPS) medicines are held (they should be 'staff only areas'). There should be no smoking, food consumption or storage of food in areas where medicines are stored or supplied, with notices in place informing staff and clients accordingly. Particular attention should be taken with fridges; the storage of medicines alongside food or laboratory samples must be avoided.

A record must be kept at the practice's main premises of all other locations where medicines may be stored (e.g. practice cars or homes where medicines are kept for on call purposes).

\section{Consulting rooms}

Medicines stored in consulting rooms should be kept to a minimum and should be placed out of sight in drawers or cupboards. There is no requirement for these cupboards to be locked, but it is considered good practice to do so if clients are left in consulting rooms unsupervised. Medicines subject to abuse should not be held in consulting rooms.

\section{Practice cars}

Medicines held in vehicles should be kept to a minimum. Only those used frequently and only sufficient quantities for immediate use should be carried routinely because the temperature within the car may fluctuate greatly causing reduced efficacy of the products. Any medicines that are kept in vehicles should be clean and well organized.

Cars should be fitted with refrigerated units for temperature sensitive medicines and the temperature of these monitored to ensure they are maintained between $2^{\circ} \mathrm{C}$ and $8^{\circ} \mathrm{C}$. Temperatures should be monitored in vehicles to ensure that medicines requiring storage at a controlled ambient room temperature are not left in vehicles when temperatures exceed $25^{\circ} \mathrm{C}$ or go below $8^{\circ} \mathrm{C}$.

Precautions against theft such as not storing medicines in the car for long periods of time or overnight, not leaving medicines on display, and parking vehicles in secure areas should be considered. Controlled drugs (CDs) should be stored in either a locked glove box or in a separate locked bag, box or case that is removed from the vehicle if it is left unattended for any significant period of time.

(9) See also Controlled Drugs.

\section{The dispensary}

Care should be taken to ensure safe storage of all medicinal products. Medicines must be stored in accordance with the manufacturer's SPC or datasheet. SPCS for all UK authorized veterinary medicines can be found in the VMD product information database (@)). 
Medicines should be protected from environmental conditions that may damage or degrade them such as light, temperature and humidity. Storing products in their original packaging will give the best protection against environmental damage. The dispensary should also be fitted with blinds on any windows to protect against bright light, and light sensitive products should be kept in their outer packaging. Ventilation must be adequate, and hot water sterilizers and autoclaves should not be used in the dispensary because they may adversely affect the humidity of the room.

To avoid contamination, medicines should not be stored in toilet or washing areas, or laboratories. Medicines to be supplied to clients should not be stored in areas where animals are kept such as kennels, except those medicines already dispensed.

Flammable products must be stored in an appropriate flammables cabinet specifically designed for this purpose, preferably on the floor to prevent breakages.

Shelving should be of sturdy construction and well designed to reduce the possibility of breakage and spillage. It should be designed in such a way to ensure medicines are easy to locate with areas suitable for small and bulk storage.

Medicines should be protected from dust and dirt and a regular cleaning schedule should be developed to maintain a high standard of cleanliness

\section{Temperature monitoring}

Particular attention should be paid to ensure medicines are stored at the correct temperature in accordance with the SPC. Products to be stored at a controlled ambient room temperature do not require refrigeration and should be kept between $8^{\circ} \mathrm{C}$ and $25^{\circ} \mathrm{C}$. Storage of products at a controlled ambient temperature should be monitored if the temperature is outside this range or remains unusually high or low for any significant period of time.

Products that require refrigeration such as vaccines, insulin, antisera and some reconstituted antibiotics must be stored in a fridge between $2^{\circ} \mathrm{C}$ and $8^{\circ} \mathrm{C}$. These products should be removed from the delivery cool chain as soon as possible and stored in a fridge. They should only be removed from the refrigerator for immediate use.

Care should be taken to ensure the refrigerator maintains a temperature between $2^{\circ} \mathrm{C}$ and $8^{\circ} \mathrm{C}$. Thermometers must be appropriately situated within the fridge (i.e. not touching the chiller plate and not placed in a compartment away from the veterinary medicines). Temperatures should be monitored at least daily, and this should ideally be the responsibility of a named person(s). Maximum/

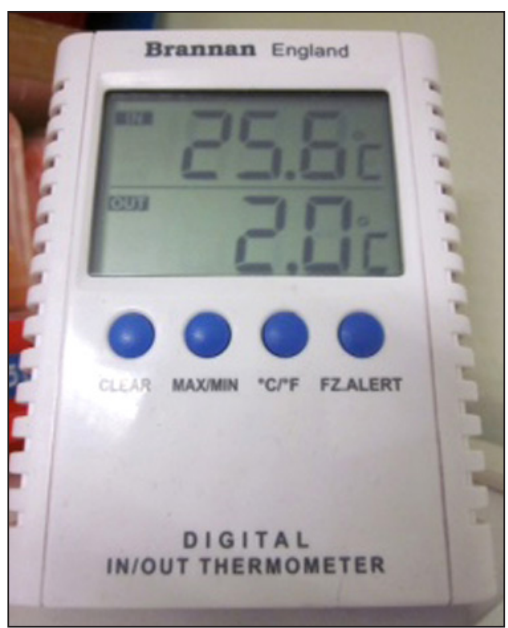
minimum thermometers and a log book can be used for this purpose. The thermometers should be reset after the readings have been recorded.

A written plan should be in place detailing the actions to be taken should temperatures in the dispensary or refrigerator fluctuate outside the recommended temperatures. For example, this may include the direction to dispose of insulin if the temperature drops below $2^{\circ} \mathrm{C}$ or that further information should be sought from the medicine manufacturer if the temperature of the fridge was maintained above $8^{\circ} \mathrm{C}$ for longer than a few minutes.

Regular cleaning, servicing and stock control in refrigerators should be performed as for other storage areas. It is good practice to have a separate shelf or area available for medicines that have been prepared for collection by an owner or for use by an in-patient.

The use of continuous data loggers to monitor the temperature can be convenient, but these should only be used if an audible alarm or flashing light alarm alerts the user to temperatures deviating from the required range. Weekly downloading of the temperatures into graph format is useful to determine trends in temperature fluctuations, but notice of temperatures outside the required range comes too late to prevent the product being used if an audible alarm is not present. Data loggers should be downloaded at least weekly.

Practice cars should be fitted with refrigeration units and monitored in the same way as the practice fridge.

\section{Stock control}

Efficient stock control allows you to have the right product at the right place at the right time. It ensures that capital is not tied up unnecessarily and protects against problems arising in the supply chain.

\section{KEY POINTS}

- Stock control processes must be in place to ensure medicines are used or disposed of within their shelf-life (including their in-use shelf-life)

- Good stock control will reduce waste and save money

- It is an offence to supply or administer an out of date medicine, including veterinary medicines which have exceeded their in-use shelf-life opening 
- Set stock levels to allow accurate stock holding

- Have a named person(s) responsible for stock control

- Store products in original packaging, in a logical order

- Supply a product leaflet or SPC with all products dispensed

- Dispense products with the shortest expiry date first

- Store products with different batch numbers together.

Dates of deliveries and items delivered from manufacturers or wholesalers should be recorded unless this information is on the retained invoice or delivery note. Packs with damaged or defaced packaging and out of date stock should be stored separately while awaiting disposal. Once stock has been dispensed and taken from the practice premises it should not be accepted back into the dispensary unless correct storage during this time can be guaranteed. The batch number of products dispensed for administration to food producing animals must be recorded on the case file for batch tracking purposes. For small animals it is enough to record the date of first usage of each box or bottle.

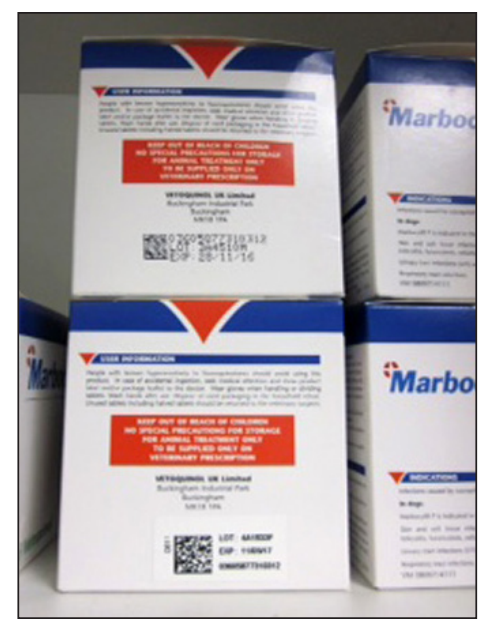

\section{Stocking levels}

In order to perform stock control effectively, stock order levels (maximum and minimum) must be set for every product. This could be done using a small card placed on the products at the correct place, a sticker on the shelf or a fully automated system. Any system will require information such as product description, order up to level (OUTL), reorder point (ROP), supplier, item code, etc

The amount of stock to be kept can be calculated using this basic equation: OUTL = D X L ( $D$ = daily demand; $L=$ lead time $)$.

In practice, however, average daily demand is very difficult to calculate accurately and does not take weekends, public holidays or periods of exceptional use into account. It may be better to work on a principle of 2 or even 4 weeks cover so the average daily demand becomes the average demand for 2 or 4 weeks. This will allow sufficient stock to cover for any emergencies. It may be wise to keep 4 weeks cover of any medicines used in emergency situations but only 2 weeks of routine products where the consequences of not having a bottle in stock are not so high. If the item is seasonal, extra consideration will be needed to set an OUTL which may be different for specific seasons.

Repeat orders can be a cost effective way of ordering stock for frequently used products. It must be recognized, however, that the product will have been bought and paid for within a month. Until enough stock is sold to cover what has been paid, the practice will be out of pocket. If just 2-4 weeks supply is ordered, you should always have sold the stock on by the time you come to pay the wholesaler for it, which helps with cash flow.

Products subject to intermittent use will not fit into the calculation of OUTL. For example, some emergency medicines are used infrequently but when required, large volumes may be used. This needs to be factored in when OUTLs are set.

Stock control is an ongoing process. Stock levels should be altered as new products are brought to the market or preferences change.

\section{Stock rotation}

Products with the shortest expiry should be dispensed first to reduce the number of products going out of date. This can generally be achieved by ensuring that all new stock from deliveries is placed at the bottom or back of current stock, but it is useful to double check the expiry dates of the newly delivered stock are longer than current stock, particularly if orders are placed with different companies.

\section{Stock loss and annual stocktake}

There are a number of reasons for stock loss within a veterinary practice. These include:

- Products going out of date

- Broken or damaged stock

- Items mistakenly not charged for

- Theft

- Items charged for by wholesalers but not received

- Wholesaler credit for goods returned or missing not received

- Consumable wastage.

Products going out of date means money lost to the practice. Setting appropriate ROPs and OUTLs will reduce stockholding and lead to fewer products going out of date. Monthly date checking should be performed to ensure products are used before they expire (where clinically appropriate). 
The VMD requires all practices to perform an annual stocktake where incoming and outgoing medicinal products are reconciled. Any missing items must be accounted for. Out of date products are considered 'stock' until they are removed from the stockfile. In the annual stocktake, all products that have gone out of date must be accounted for or they will be assumed to be missing. Broken or damaged stock should also be recorded for stocktaking purposes. A system should be put in place to ensure all items used are charged for appropriately. This will ensure not only that the practice maximizes their income, but that purchases and sales of each product can be reconciled for the annual stocktake. (9) See also Record keeping and audits.

To prevent the theft of medicines, food and pet products, ensure clients do not have access to medicine cupboards when left alone in the consulting room and ensure any waiting room displays are within sight of reception staff. Regular stocktakes of vulnerable items should be performed to check for discrepancies.

Medicines received from wholesalers should always be checked against delivery notes and any missing or damaged goods claimed for at the time of receipt. Once a claim has been made, ensure the credit is received by reconciling credit notes against returns books.

It is advised that practices set up a dummy client called 'Disposal' on their practice management system and record all medicines that are unusable. This can help the practice identify where medicines are being wasted and also help with reconciling stock during audits.

\section{Medicine returns}

As correct storage conditions (and therefore safety and effectiveness) of medicines returned by owners cannot be guaranteed, such products should be disposed of and not accepted back into stock unless the practice can guarantee that the product has been stored according to its SPC. Products dispensed for animals on the premises that have not left the practice can be accepted back into stock, providing the storage conditions are known to be acceptable and they are not contaminated in any way (e.g. by using the same syringe to withdraw multiple oral doses from a bottle of liquid medicine).

Unwanted or mistakenly ordered medicines should be returned to wholesalers as soon as possible. There may be restrictions on such returns as returned medicinal products may be destroyed.

\section{Expiry dates and in-use shelf-life}

It is illegal to supply or administer a medicine after the expiry date detailed on the pack or to obscure the expiry date on the packaging of any medicine. Requirements in EU and national legislation to ensure the stability and safety of the produce mean that some products such as injectables have an in-use shelf-life.

Any medicine which is stipulated to be used within a given timeframe should be marked with the date of opening and use by date. This is the length of time after which the product must be disposed of upon opening. For most multidose injectables, the in-use shelf-life is usually, but not always, 28 days, thus making it an offence to administer the product after 28 days of opening (unless the expiry date of the product itself is shorter; check the bottle for details).

Multidose vials should be marked with the date of first opening and the use by date. Bright stickers can be useful to draw attention, but all multidose vials with an in-use shelf-life now have a space to write this information. Any medicine left in the vial after the specified time must be discarded. For single-use ampoules, the required dose should be withdrawn immediately and the remainder disposed of. Oral liquids should generally be disposed of 6 months after opening. Care should also be taken with some medicines that are sensitive to humidity as these may have an in-use shelf-life stated on the SPC.

A named person(s) should be in charge of date checking the medicine store once a month and a log should be kept of this check. When date checking, short dated stock should be marked as such and brought to the front of the shelf to be used first. Any stock that has gone out of date should be separated and recorded before destruction.

\section{Broken or damaged medicines}

Any medicine with a broken or damaged container should be segregated immediately for safe disposal. Care should be taken with spilled or leaked medicines. Check the SPC and COSHH assessments to identify if the medicinal product is hazardous before cleaning takes place, and use appropriate personal protective equipment if advised. A spill kit should contain gloves, absorbent material and a laminated copy of the SOP for dealing with spillages. Spill kits for cytotoxic spills should contain overshoes, gloves, a gown, 'chemosorb pads', disposable bags and a step-by-step users guide.

\section{Dispensary management}

\section{KEY POINTS}

- A single person should be responsible for dispensary management

- A dispensary manual should be written detailing standard operating procedures (SOPs) and risk assessments

- All staff involved in medicines handling should be suitably trained

One person should be responsible for ensuring the legal requirements, safety assessments and best practice procedures are carried out. This person should be responsible for ensuring:

- The layout of the dispensary is efficient and appropriate shelving is used

- The dispensary is always clean and tidy

- Date checking is performed and recorded regularly 
- SOPs are written and implemented

- Stock control is efficient to reduce stock loss

- Storage conditions (particularly temperature) are monitored in the dispensary and practice cars.

\section{The dispensary manual}

A dispensary manual should be prepared containing standard operating procedures (SOPs), risk and Control of Substances Hazardous to Health (COSHH) assessments, blank forms and other useful information (e.g. on special suppliers and unusual products). This should be available to and read by all those involved in dispensing medicines.

\section{Staff training}

All those involved in medicine supply should be suitably trained. To prevent both contamination of the medicinal products and to protect the staff member, training should include the requirement for a high standard of personal cleanliness, with regular hand washing seen as essential and open wounds covered at all times. Staff should also be trained on how to avoid direct contact with medicines, such as wearing gloves or using a tablet counting triangle and spatula.

Although there is no legal requirement for staff members working in the dispensary to have formal training, all staff members should have read the dispensary manual and be aware of practice SOPs and risk assessments.

The RCVS Practice Standards Scheme (PSS) requires at least one member of staff in veterinary hospitals to have completed a dispensing course such as the BSAVA dispensing course, the University of Glasgow dispensing course or similar in the last 5 years. The National Proficiency Test Council (NPTC) provides competency testing in the safe use of veterinary medicines. It should be considered best practice for the person responsible for dispensary management to have completed one of these courses.

\section{Standard operating procedures}

\section{KEY POINTS}

- SOPs ensure staff and patient safety

- SOPs should be written in an appropriate format depending on the task described

- SOPs should be written by someone performing the task regularly and reviewed by someone who does not know the task

- SOPs should be reviewed regularly

A standard operating procedure (SOP) is a written document describing routine procedures carried out in veterinary practice. Well written SOPs provide direction, improve communication, reduce training time and improve work consistency. SOPs should be:

- Provided for all staff members

- Regularly reviewed

- Designed according to practice policy.

Use of SOPs may be taken, along with relevant training and continuing professional development (CPD), as sufficient evidence that staff are regarded as 'competent' under the requirements of the Veterinary Medicines Regulations (VMR).

Benefits of implementing SOPs include:

- Providing assurance of the quality of the service

- Ensuring the achievement of good practice

- Enabling veterinary surgeons to delegate and so free time up for other duties

- Avoiding confusion over who does what

- Providing advice and guidance to locums and part-time staff

- Providing a useful tool for training new staff members

- Contributing to the audit process

- Providing financial benefits

- Most importantly, protecting staff and clients.

SOPs can be written in four different formats: simple steps; hierarchical steps; graphic procedures; or a flowchart. The most appropriate format to use will depend on the number of steps involved in the process and how many decisions the user has to make during the procedure.

\section{Simple steps}

Many tasks in a veterinary practice, such as cleaning kennels, are repetitive and require few decisions to be taken. For these tasks, a simple set of steps to be carried out is sufficient detail to enable a member of staff to complete the procedure. The SOPs entitled 'Using ampoules' and 'Date checking the dispensary' (see later) are examples of this type of format. Unfortunately, due to the low level of detail, there is room for staff to misinterpret the procedure. For more detailed procedures, a hierarchical step SOP may be more appropriate. 


\section{Hierarchical steps}

This format produces very detailed and precise SOPs, which in turn produce consistent work patterns. Simple steps are broken down into more detailed subsections, detailing exactly what the operator is required to do. Experienced staff members may only need to look at the subsections occasionally, whilst new staff can use the subsections to help learn the procedure. The SOP entitled 'Receiving a Schedule 2 or 3 Controlled Drug' (see later) is an example of this type of procedure.

\section{Graphic procedures}

If the procedure is a long process, a graphic SOP should be considered. These break down longer tasks into shorter subprocesses that consist of only a few steps. Photographs and diagrams can also be used to illustrate the procedure. These can be supplemented with explanatory text and are useful when a process would require a lengthy description if written in words. The SOP entitled 'Recapping needles' (see later) is an example of this type of procedure.

\section{Flowcharts}

Procedures that require many decisions should be written as flowcharts. These are simply a graphical way of presenting the logical steps in a decision making process. This style of SOP is useful when a staff member has to make decisions on how to progress with a procedure. A simple example of this is shown in the SOP entitled 'Medicines returned by customers or not used by in-patients' (see later). There are generally accepted symbols for flowcharts, which should be used. These are:

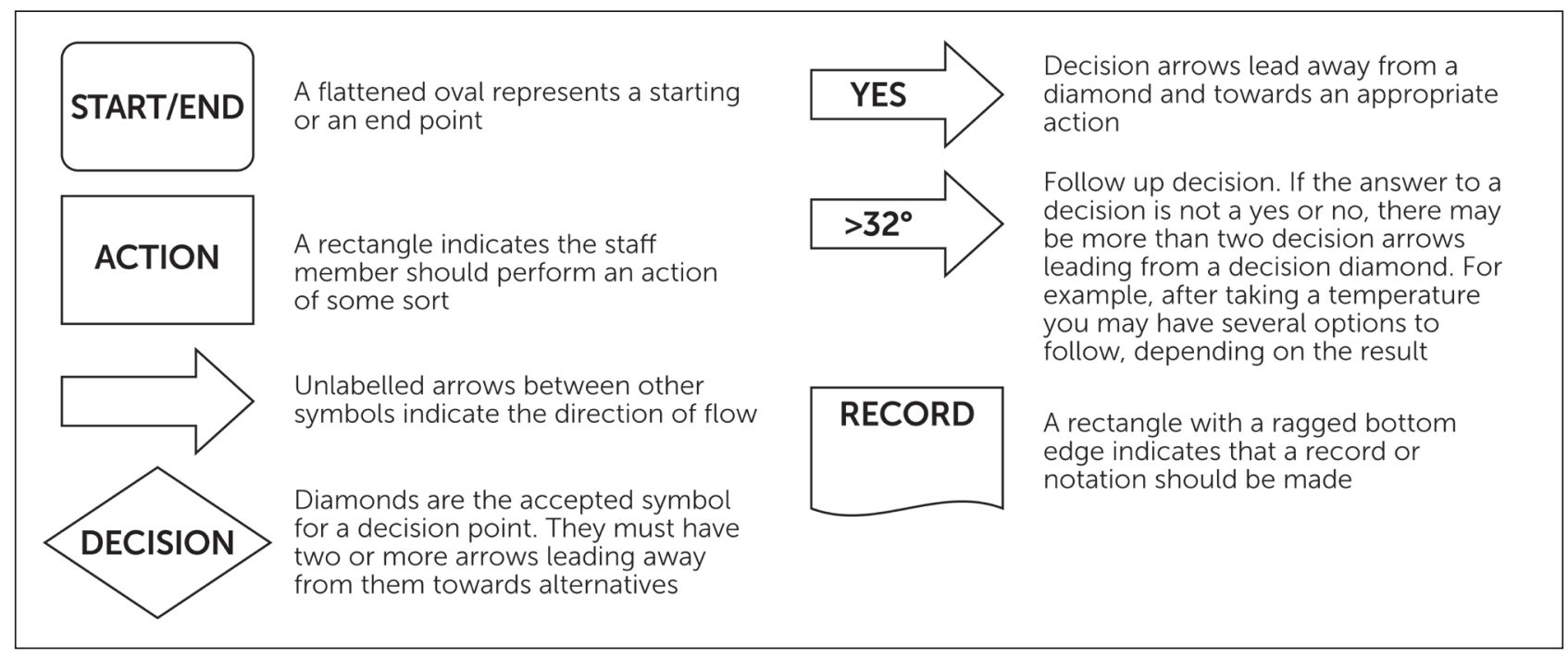

\section{How to write a standard operating procedure:}

1. Decide on the purpose (e.g. how to receive a medicine from a wholesaler).

2. Decide on the author. This should be someone who performs the task regularly.

3. Draft the content. An SOP should include:

- The method of carrying out the procedure in sufficient detail and in logical steps

- A list of personnel by job description who can carry out the procedure

- Where in the practice the procedure may be undertaken

- The identity of the person in overall control of the procedure in the practice

- The date of implementation

- The date of review.

4. Consult others. Ideally, input from someone new to the task should be sought to ensure the information is clear and detailed enough, as well as from someone who knows the task well to point out anything that may have been missed.

5. Once the final draft is complete, the SOP should be put into circulation. It may be useful to ask staff to sign to say that they have read and understood the document.

6. Once accepted, the SOP should be named and possibly numbered if the practice has many SOPs.

7. SOPs should be reviewed regularly.

If something goes wrong when a novice member of staff performs an activity after reading an SOP, the SOP is not detailed enough or written logically and should be reviewed.

Some examples of SOPs are shown below. These examples are illustrative and should be adapted according to practice policy. 


\section{USING AMPOULES}

1. Injectables should be treated as intended for single use only unless the label specifically indicates that they are authorized and intended for use on more than one occasion. When a dose is decided upon, the closest volume ampoule should be chosen for dispensing.

The correct volume should be drawn up and the remainder of the ampoule drawn into a second syringe for disposal. If it is a Controlled Drug, the remainder should be added to a denaturing container; this does not need to be witnessed by an independent witness, but it is good practice for it to be witnessed in-house. (9) See also Controlled Drugs.

3. The disposed remnant should be recorded as a whole medicine for disposal and placed in the Medicines Waste Bin or 'Pharmy Bin'

4. The empty ampoule should be placed in the sharps bin.

5. If the drug is a Schedule 2 Controlled Drug, a record must be made in the Controlled Drugs Register. You should note the amount used and the amount discarded; for example, if you used $0.5 \mathrm{ml}$ from a $1 \mathrm{ml}$ ampoule, the Register should read " $0.5 \mathrm{ml}$ given and $0.5 \mathrm{ml}$ wasted".

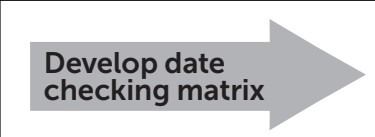

Ensure all areas of the pharmacy are included.

All areas should be date checked every 3 months following the date checking matrix, ideally by the same staff member

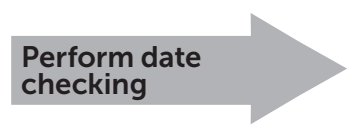

As each area is checked, move stock with the shortest expiry date to the front and stock with the longest expiry date to the back. Identify stock with less than 4 months shelf life and record short dated items in a book used for this purpose. Highlight short dated stock with short dated stickers.

Remove out-of-date stock. Place this stock in a location, differentiated from normal stock - clearly marked 'Out of Date' stock, whilst you complete the rest of the date checking.

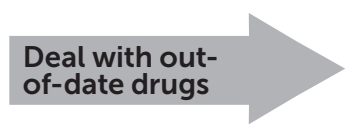

Record quantities and values of out of date medicines for accounts purposes and annual audit and dispose of this stock appropriately in a pharmaceutical waste bin.

\section{Complete matrix}

Record completion of date checking of each area on the matrices by initialing and writing the date of completion in the relevant box. Every 4 weeks, check the short dated stock book and remove any out-ofdate stock.

Retain matrices for 6 months. The matrices must be available for inspection by authorized persons.

\section{RECEIVING A SCHEDULE 2 OR 3 CONTROLLED DRUG}

1. Check that any packages received are intact and not damaged.

a. If the stock that has been received is damaged or incorrect, contact the supplier and notify them immediately.

b. Complete a returns form according to the SOP 'How to return medicines to the wholesaler', but continue with steps 2-6.

2. Immediately open the package(s) containing the $\mathrm{CD}(\mathrm{s})$ and check the stock received against the invoice and delivery note or the request made to another pharmacy.

a. Check the product name, strength, dosage form, pack size, expiry date and that the manufacturer's tamper-evident seal is intact.

3. If the $C D$ that has been received is a Schedule $2 C D$, make a record in the relevant section of the $C D$ Register.

a. Information to record: Date of receipt of drug, amount received, name and address of company you received the drug from, running balance.

b. Make a manual count of the stock received and any stock already held to ensure that the resulting balance is correct. If there is any discrepancy, notify the person in charge.

c. If the CD is damaged or irretrievable, a veterinary surgeon should make a footnote to indicate this and ask a second person to sign the record to confirm that the stock was received in this condition.

4. Store all Schedule 2 and 3 CDs requiring safe custody in the CD cupboard.

a. Damaged stock should be stored in the CD cupboard, in a sealed bag, clearly marked as "Damaged Stock".

5. When any damaged/incorrect stock is returned to the supplier, ensure records of the return are made in the CD Register.

a. Information to record: date of return, amount returned, name and address of person or firm returned to, running balance.

6. It is good practice to keep invoices for all CDs for 2 years. 


\section{RECAPPING: THE 'ONE-HAND' TECHNIQUE}

Many accidental needlestick injuries occur when staff are recapping needles. Recapping is a dangerous practice: if at all possible, dispose of needles immediately without recapping them.

If it does become necessary for you to recap a needle (e.g. to avoid carrying an unprotected sharp when immediate disposal is not possible), do not bend or break the needle and do not remove a hypodermic needle from the syringe by hand.

To safely recap needles, use the 'one-hand' technique:

\section{Step 1}

Place the cap on a flat surface, then remove your hand from the cap.

\section{Step 2}

With one hand, hold the syringe and use the needle to 'scoop up' the cap.

\section{Step 3}

When the cap covers the needle completely, use the other hand to secure the cap on the needle hub.

Be careful to handle the cap at the bottom only (near the hub).

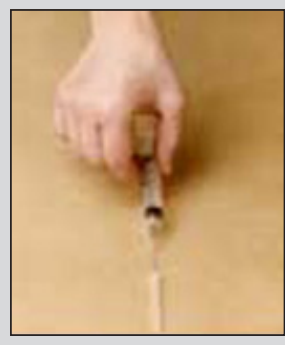

Step 1

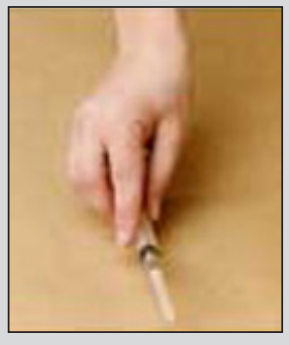

Step 2

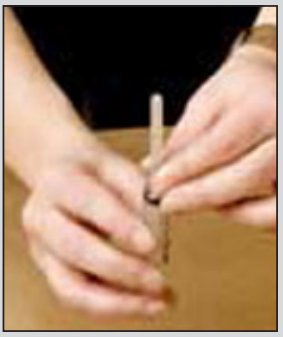

Step 3

\section{Medicines returned by customers or not used by in-patients}

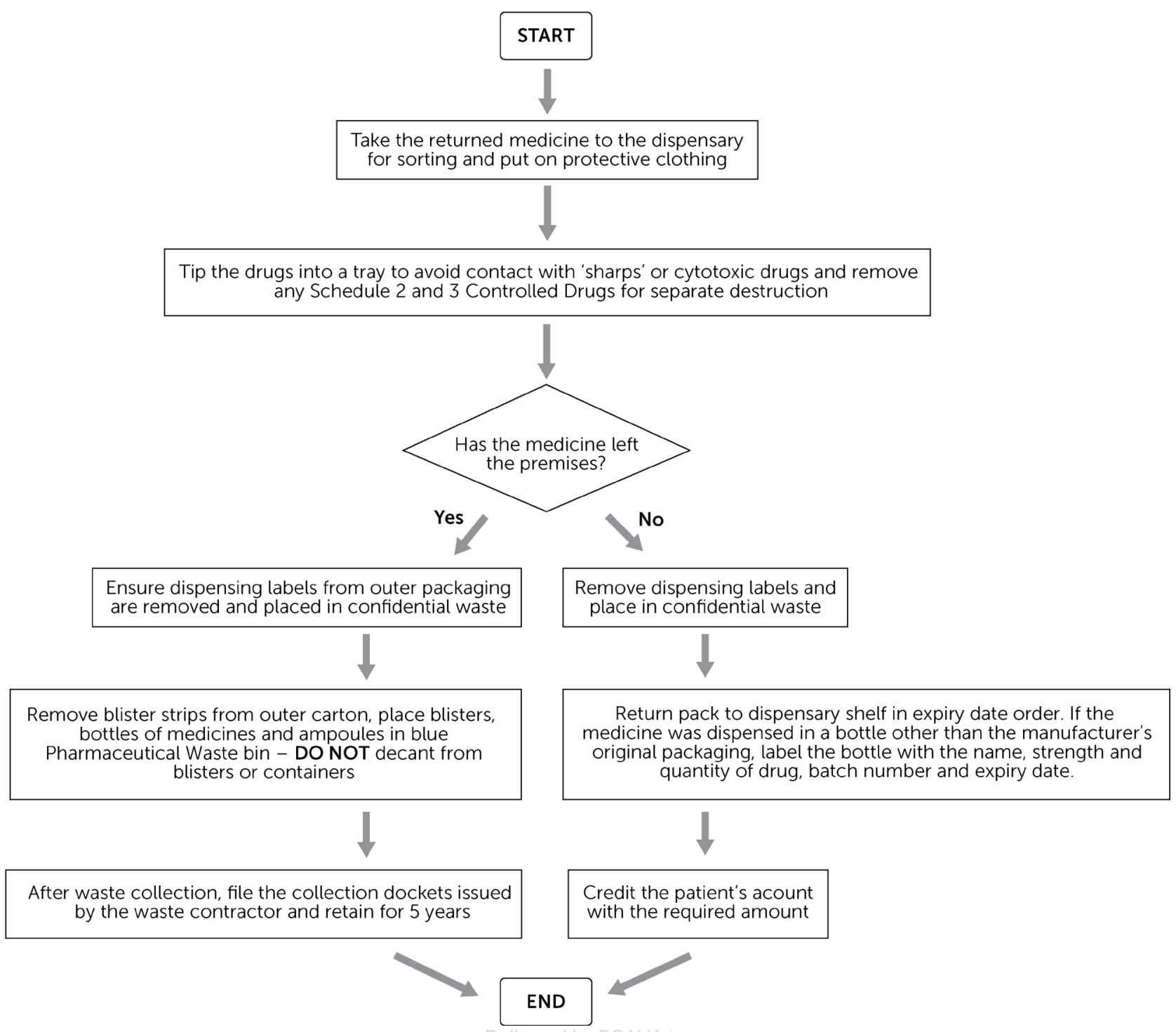




\section{QUESTIONS}

1. Temperature-sensitive vaccines should normally be stored between:
a. $10-12^{\circ} \mathrm{C}$
b. $2-8^{\circ} \mathrm{C}$
c. $-1-3^{\circ} \mathrm{C}$
d. $10-14^{\circ} \mathrm{C}$

2. Once opened, most multidose injection bottles must be discarded after:
a. 14 days
b. 24 hours
c. 1 month
d. 28 days

3. Medicines returned by customers:
a. May be returned to stock and resold
b. Must be disposed of unless the practice can guarantee they have been stored according to their SPCs
c. May be used in-house
d. Should be returned to the wholesaler

4. Dispensary SOPs can be used in practice to:
a. Show evidence that staff are competent to hand over medicines
b. Ensure consistency
c. Reduce errors
d. All of the above

5. Standard operating procedures should be written by:
a. Someone familiar with the task
b. Someone unfamiliar with the task
c. The practice manager
d. The head nurse

6. The estimated amount of stock that should be held can be calculated using the equation:
a. $O U T L=D \times L$
b. $D=O U T L / L$
c. $D=L \times O U T L$
d. $O U T L=D / L$ 